\title{
An emissivity-corrected method for the accurate radiometric measurement of transient surface temperatures during braking
}

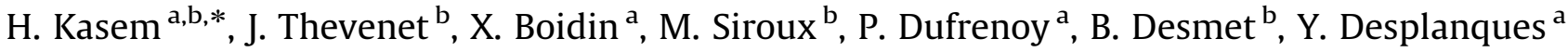 \\ a Laboratoire de Mécanique de Lille (LML UMR CNRS 8107), USTL, Univ. Lille Nord de France, F-59655 Villeneuve d'Ascq Cedex, France \\ ${ }^{\mathrm{b}}$ Laboratoire de Mécanique et d'Energétique (LME), UVHC, Univ. Lille Nord de France F-59313 Valenciennes, France
}

\section{A R T I C L E I N F O}

\section{Article history:}

Received 7 September 2009

Received in revised form

13 January 2010

Accepted 22 January 2010

Available online 4 February 2010

Keywords:

Braking

Radiometric measurements

Two-colour pyrometer

Emissivity variation

\begin{abstract}
A B S T R A C T
The main difficulty encountered in brake disc infrared temperature measurements is the lack of knowledge of the disc surface emissivity, which is nonuniform and varies during braking. To provide information on the nonuniformity and variations of emissivity, brake disc surface temperatures were investigated by an original two-colour fibre optic pyrometer and an infrared camera. The first result is the measurements of the accurate surface temperature. Besides, it is shown that the local emissivity varies with friction due to modifications of surface properties. Thermal phenomena observed on the disc track are correlated with temporal changes of normal and tangential frictional forces.
\end{abstract}

(c) 2010 Elsevier Ltd. All rights reserved.

\section{Introduction}

During railway braking, the frictional heating can raise the brake disc temperature to a point where thermal stresses generate surface degradations such as thermo-mechanical failure, in particular cracking [1-3], but also chemical damage such as oxidation [4]. The determination of the limits of friction brakes is generally associated to the thermal levels attained (real surface temperature), from which the thermomechanical loading can be determined [5]. Nevertheless, thermal measurements during braking remain a delicate task because of the very high rotation speeds [6], especially during a high speed train emergency braking when the observation time is under $1 \mathrm{~ms}$. Other difficulties are the variation of the nonuniform surface state and time-varying due to friction and heterogeneity of the 3rd body [7], surface oxidation and nonuniform real zones contact which move during braking [8].

Two categories of methods are usually employed for thermal measurements in braking. The first method is a direct contact technique by means of thermocouples embedded in the disc and the pad [9-11]. Thermocouples are usually located at a distance between 1 and a few millimetres from the rubbed surface. However, the temperature measured by this direct contact method corresponds to the temperature of the subsurface and not to that of the surface. The second method is a measurement without contact (also

\footnotetext{
* Corresponding author at: Universite' des Sciences at Technologies de Lille, Polytech' Lille bâtiment D-bureau 238, Avenue Paul Langevin, 59655 Villeneuve d' Ascq Cedex, France. Tel.: +33320436514; fax: +33320337153.

E-mail address: haytam.kasem@polytech-lille.fr (H. Kasem).
}

called radiometric measurement) which consists in measuring the temperature of the surface by thermography [12-14] and pyrometry [15]. However, the main difficulty of radiometric measurements is the necessity of the disc emissivity knowledge, which varies during braking with the surface state and temperature [16-18].

The purpose of this paper is to provide information on the nonuniformity and variations of emissivity during braking. The brake disc surface temperature was studied by using a specific fibre optic two-colour pyrometer developed for braking applications [19] and an IR camera. The fibre optic two-colour pyrometer allows one to obtain the brake disc surface temperature and emissivity variations during braking. Thermal phenomena observed by two-colour pyrometry on the disc-track are correlated to the evolution of normal and tangential frictional force. Finally, the values of the surface emissivity identified by the two-colour pyrometer are reintroduced in the measures obtained by the IR camera which allows one to estimate the errors of surface temperature measurements due to the unknown emissivity.

\section{Experimental set-up}

\subsection{Tribometer}

Braking experiments were performed on a pin-on-disc braking tribometer developed in the Laboratoire de Mécanique de Lille. The performances of the tribometer used made it possible to reproduce at reduced-scale stop-braking loading conditions and thermal levels reached during railway stop-braking at full-scale 


\section{Nomenclature}

$C_{1} \quad$ first Planck constant, $\mathrm{W} \mathrm{m}^{2} \mathrm{sr}^{-1}$

$C_{2} \quad$ second Planck constant, $\mathrm{m} \mathrm{K}$

$L \quad$ luminance, $\mathrm{W} \mathrm{m}^{-3} \mathrm{Sr}^{-1}$

$S \quad$ detector signal, $\mathrm{V}$

$T \quad$ temperature, $\mathrm{K}$

$t \quad$ time, s
Greek symbols

$\varepsilon \quad$ emissivity

$\lambda \quad$ wavelength, $\mu \mathrm{m}$

$\mu \quad$ friction coefficient

Subscripts

1 detector 1 of the two-colour pyrometer

2 detector 2 of the two-colour pyrometer
[20]. To reproduce the surface mean temperature elevations observed at full-scale, a scale conversion rule was developed [21]. The parametric triplet composed of the mean contact pressure, initial sliding velocity and braking duration was chosen to reproduce thermal loadings observed at full-scale.

Figs. $1 \mathrm{a}$ and $\mathrm{b}$ give a general view of the tribometer with its test chamber closed and open, respectively. The view of the open chamber shows the disc mounted on the axle on the left side while the pad is visible on the right side mounted on the chamber's door. Fig. 1c presents a schematic drawing of the tribometer. An electric motor drives the disc in rotation up to $4000 \mathrm{rpm}$ (i.e. a maximal sliding velocity of $70 \mathrm{~m} \mathrm{~s}^{-1}$ with the maximal radius of $160 \mathrm{~mm}$ ). The control of the disc rotation enables one to develop a simulated inertia around the flywheel which has its own inertia of $3.35 \mathrm{~kg} \mathrm{~m}^{2}$. The hydraulic actuator applies a normal load up to $1200 \mathrm{~N}$ on the pad. The tribometer instrumentation is composed of a tachymeter for the rotation speed measurement and a 3D piezoelectric sensor for pads on disc load measurements for the calculation of the friction coefficient $\mu$.

\subsection{Temperature measurements during stop-braking experiments}

The disc surface temperature was estimated by:

- An infrared CEDIP camera (JADE, InSb detectors $256 \times 320$ pitch: $30 \mathrm{~mm}$, temperature range: $0-1200{ }^{\circ} \mathrm{C}$, maximum frequency acquisition 170 frames/s, spectral range: $3-5 \mu \mathrm{m}$ ). Using an objective of $100 \mathrm{~mm}$, the IR camera was located $1 \mathrm{~m}$ from the rubbed surface and the lower-right part of the disc was observed (Fig. 2).

- An optical fibre two-colour pyrometer developed for braking application (HgCdTe detectors, temperature range: 200$1000{ }^{\circ} \mathrm{C}$, response time: $8 \mu \mathrm{s}$ ) which was placed on the average frictional radius $(100 \mathrm{~mm})$ at $90^{\circ}$ from the pad-disc contact centre (corresponding to an angular length of $157 \mathrm{~mm}$ ) in the top-right corner of the IR camera observed area (see Fig. 2). The optical fibre was held in place by a black mounting bracket which was kept near room temperature in order to avoid reflections on the brake disc surface. The distance between the fibre and the rubbed surface of the disc was $5 \mathrm{~mm}$ giving a spot diameter of $2.4 \mathrm{~mm}$ [19].

The two-colour pyrometer is composed of two HgCdTe detectors equipped with two bandwidth filters $\left(\lambda_{1}=2.55 \mu \mathrm{m}\right.$ and $\left.\lambda_{2}=3.9 \mu \mathrm{m}\right)$, a fluoride glass optical fibre and a data conditioning and acquisition device. The two-colour pyrometer measures the radiated energy of the brake disc for the two bandwidth filters (central wavelength $\lambda_{1}$ and $\lambda_{2}$ ) $[19,22,23]$ :

$$
\begin{aligned}
& S_{\lambda_{1}}=A_{\lambda_{1}} \cdot L_{\lambda_{1}}=A_{\lambda_{1}} \cdot \varepsilon_{\lambda_{1}} \cdot C_{1} \lambda_{1}^{-5} \exp \left(-C_{2} / \lambda_{1} T\right) \\
& S_{\lambda_{2}}=A_{\lambda_{2}} \cdot L_{\lambda_{2}}=A_{\lambda_{2}} \cdot \varepsilon_{\lambda_{2}} \cdot C_{1} \lambda_{2}^{-5} \exp \left(-C_{2} / \lambda_{2} T\right)
\end{aligned}
$$

a

b

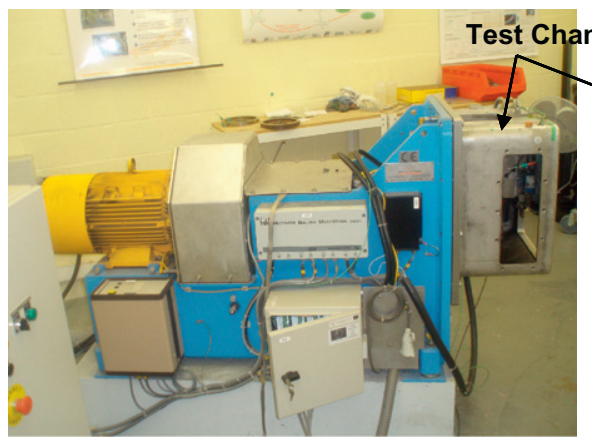

b
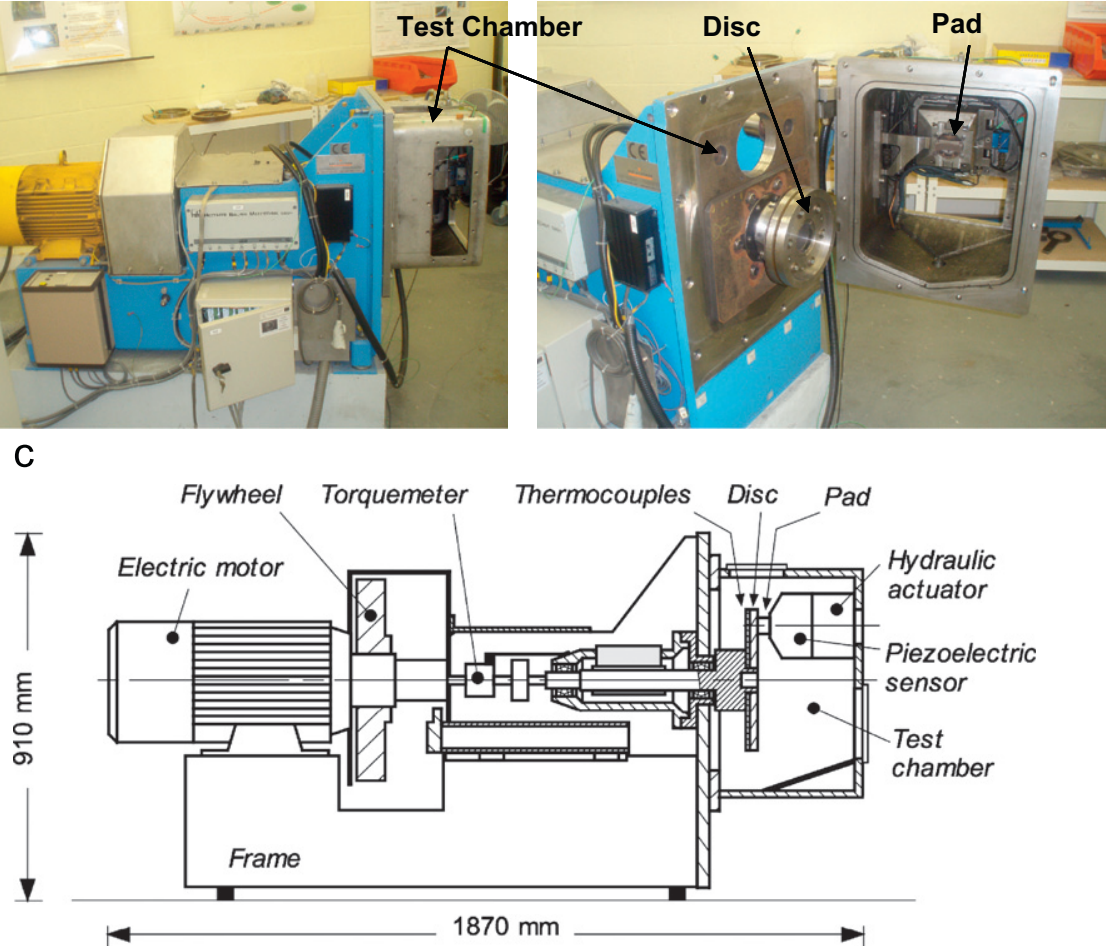

Fig. 1. View of the tribometer with its test chamber (a) closed and (b) open. (c) Schematic drawing of the tribometer. 


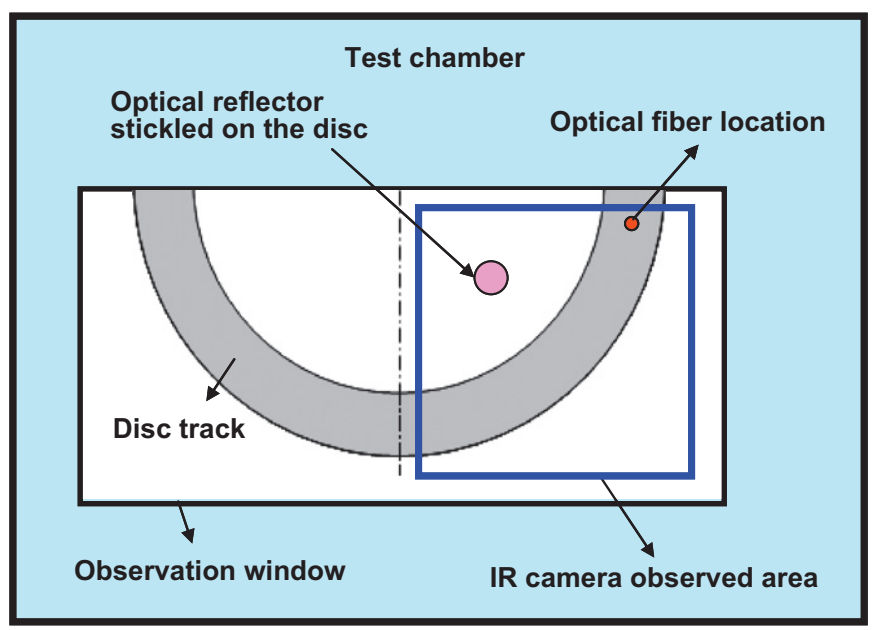

Fig. 2. Schematic representation of the observed area by the IR camera and the optical fibre two-colour pyrometer.

with $A_{\lambda}$ being the amplification constant for each detector, $\mathrm{VW}^{-1} \mathrm{~m}^{3} \mathrm{sr} ; L_{\lambda}$ the luminance; $\mathrm{Wm}^{-3} \mathrm{sr}^{-1} ; \varepsilon_{\lambda}$ the emissivity; $C_{1}=3.74 \times 10^{-16} \mathrm{~W} \mathrm{~m}^{2} ; C_{2}=1.44 \times 10^{-2} \mathrm{Km}$.

The disc surface temperature is determined from the voltage ratio of the wavelength outputs $S_{\lambda_{1}}$ and $S_{\lambda_{2}}$, considering grey body behaviour for the brake disc surface (the emissivity is assumed to remain constant between $\lambda_{1}$ and $\lambda_{2}$ ):

$T=\frac{C_{2}\left(\frac{1}{\lambda_{2}}-\frac{1}{\lambda_{1}}\right)}{\ln \left(\frac{S_{\lambda_{1}}}{S_{\lambda_{2}}} \frac{A_{\lambda_{2}}}{A_{\lambda_{1}}}\left(\frac{\lambda_{1}}{\lambda_{2}}\right)^{5}\right)}$

The disc surface emissivity can be calculated with

$\varepsilon=\frac{\frac{S_{\lambda_{i}}}{A_{\lambda_{i}}}}{C_{1} \lambda_{i}^{-5} \exp \left(-C_{2} / \lambda_{i} T\right)}$

The pyrometer detectors (the cooling of which is obtained by thermoelectric effect-thermoelectric cooler) detect temperatures from $220^{\circ} \mathrm{C}$ approximately. Thus the results of the twocolour pyrometer (temperature and emissivity) are only given for surface temperatures above $220^{\circ} \mathrm{C}$.

In order to synchronize both the IR camera and the two-colour pyrometer measurements, an optical Top-Tour was used which delivers a signal at each revolution reflection attached to the disc (Fig. 2). At the first signal:

- The acquisition of the two-colour pyrometer was turned on at a frequency of $1 \mathrm{kHz}$.

- The IR camera took an image at each passage of the reflection which allows one to record thermal pictures of the same area.

Knowing both the time acquisition for each image and the Top-Tour signal, it is possible to find the two-colour pyrometer measurements corresponding to the same area observed by the IR camera.

\subsection{Investigated materials}

The materials investigated are commercial frictional materials designed for railway braking applications for intra-urban travel. The frictional pair is composed of an XC-48 steel for the disc and an organic matrix composite (OMC) for the pad. The XC-48 disc has $0.48 \%$ carbon, $0.55 \%$ manganese and $0.25 \%$ silicon with
Table 1

Composition of the investigated organic matrix composite (OMC).

\begin{tabular}{llc}
\hline Shape & Nature & Vol. (\%) \\
\hline Fibre & Mineral & 20 \\
& Metallic & 8.5 \\
\multirow{3}{*}{ Particle } & Organic & 4 \\
& Solid lubricant & 18 \\
& Abrasive & 12 \\
Matrix & Metallic & 5.5 \\
& Phenolic resin & 32 \\
\hline
\end{tabular}

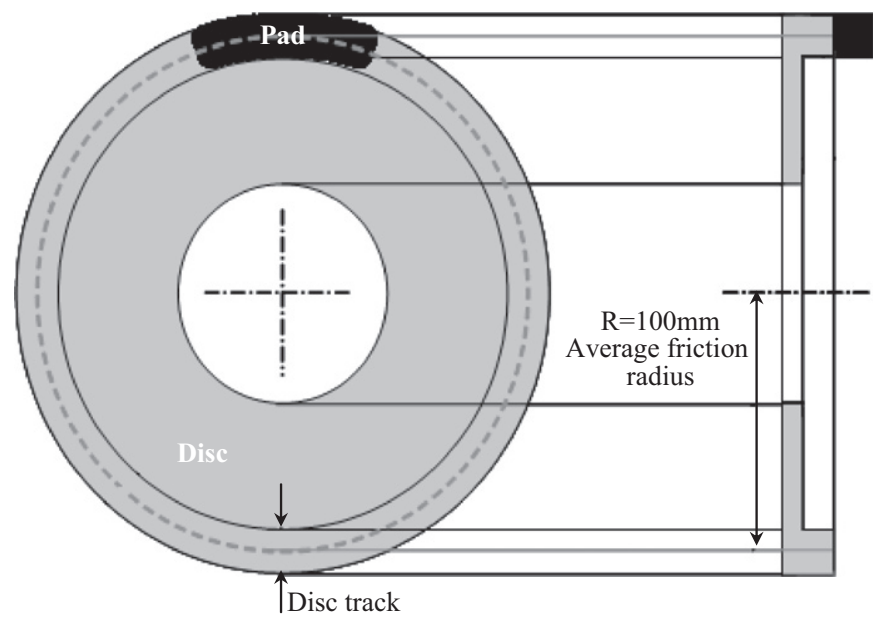

Fig. 3. Geometry of the specimens (disc and pad) and location of the thermocouples for mass temperature measurements.

hardness after tempering of 58 HRC. The composition of the OMC pad is given in Table 1 (with more than 30 components of fibres (steel, mineral fibres...) and particles (copper, brass, graphite, mineral particles...), embedded in a phenolic resin matrix.

Concerning the specimen shapes, the disc has a friction track of $16 \mathrm{~mm}$ width and $22 \mathrm{~mm}$ thickness, the average friction radius is $100 \mathrm{~mm}$. The pad has an elongated "bean" shape in the sliding direction with a width of $16 \mathrm{~mm}$, a thickness of $15 \mathrm{~mm}$ and a total angle of $39^{\circ}$ (the geometry of the specimens is given in Fig. 3). Before friction experiments, the disc was polished mechanically up to the grade 320 in order to eliminate any defects due to machining. In addition, the disc was mechanically ground a day before friction experiments by carrying-out stop-braking with small energy levels. This grinding aimed to obtain good contact conformity between both opposite surfaces (pad and disc).

\subsection{Experimental procedure}

To heat up the disc surface, several successive brakings with heat accumulation preceded the stop-braking experiments. The data acquisition was turned on when the disc surface temperature was $220^{\circ} \mathrm{C}$ (functioning temperature of the two-colour pyrometer detectors [19]). The operating experimental parameters were:

- Initial rotation speed of $1500 \mathrm{rpm}$.

- Normal force of $720 \mathrm{~N}$, which corresponds to a contact pressure of $0.6 \mathrm{MPa}$.

- Inertia of $8 \mathrm{~kg} \mathrm{~m}^{2}$.

- Initial surface temperature of $220^{\circ} \mathrm{C}$.

These operating experimental parameters were chosen to reach a total energy level of $\sim 100 \mathrm{~kJ}$, corresponding to that dissipated 
by each disc at full scale during a railway stop-braking (urban train) with initial speed $\sim 80 \mathrm{~km} / \mathrm{h}$.

\section{Results and discussion}

\subsection{Friction coefficient}

The average friction coefficient is obtained with the tangential force generated by friction divided by the normal one. Fig. 4 shows the evolution of the instantaneous friction coefficient during the braking experiments. It may be noticed that in the chosen operating conditions the friction coefficient remains globally constant from the beginning to the end of the stopbraking. The average value is around 0.33 with small fluctuations of 0.03 amplitude.

\subsection{Thermal behaviour}

\subsubsection{IR thermography of the disc track}

The IR camera was located $1 \mathrm{~m}$ from the rubbed surface and, as previously explained, only the lower-right part of the disc was observed during the braking experiments. Thermograms are recorded when the infrared camera receives a signal from the Top-Tour device. Thus, one image is taken by each disc revolution and in the same area. At this step, the temperature is calculated assuming an emissivity equal to 1 (blackbody behaviour). The visualisation of the thermography film shows the existence of two main stages during stop-braking:

- First of all, at the beginning of braking, a contact localization on the outer radius of the friction-track with the

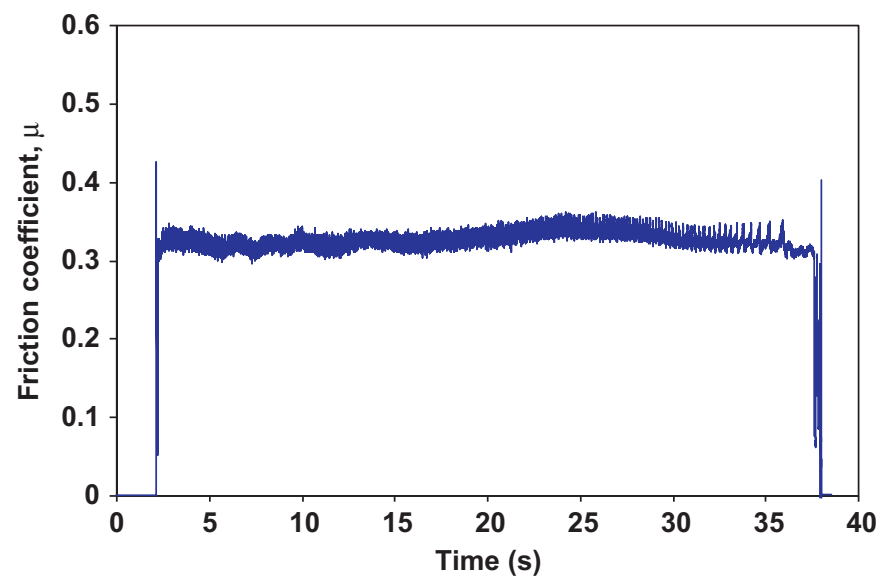

Fig. 4. Evolution of the instantaneous friction coefficient during the stop-braking experiment. formation of one hot band leading to radial thermal gradient (Fig. 5a).

- Secondly, the hot band migrates progressively from the outer radius towards the inner radius. This migration is associated with an increase of the temperature within the hot band (Figs. 5b and c).

Such phenomena (formation and migration of hot bands) are systematically observed in brakes and have already been reported in other papers in the literature $[2,3,12]$.

\subsubsection{Surface temperature and emissivity measurements by two- colour pyrometer}

Fig. 6 shows the evolution of the real temperature on the average radius of the friction track surface calculated from the signals given by the two-colour pyrometer. The temperature increase around $t=13 \mathrm{~s}$ corresponds to the formation of the hot band on the average radius (on which the two-colour pyrometer is maintained). We can also notice great fluctuations in the amplitude of temperature $\left(\sim 110^{\circ} \mathrm{C}\right)$.

Fig. 7 illustrates the evolution of the emissivity on the average radius of the friction track surface. This emissivity is calculated from the signals obtained by the two-colour fibre optic pyrometer located on the average friction radius. It can be observed that emissivity decreases significantly with the formation of the hot band on the average radius. It decreases rapidly from a value of $\sim 0.55$ at $t=10 \mathrm{~s}$ to $\sim 0.4$ at $t=13 \mathrm{~s}$, corresponding to a surface temperature around $400{ }^{\circ} \mathrm{C}$ (see Fig. 7). The emissivity then increases and stabilizes around 0.55 with fluctuations of $\sim 0.25$.

It is well established that the surface emissivity value mainly depends on several factors: temperature, wavelength, surface roughness and physicochemical properties [24,25]. In order to

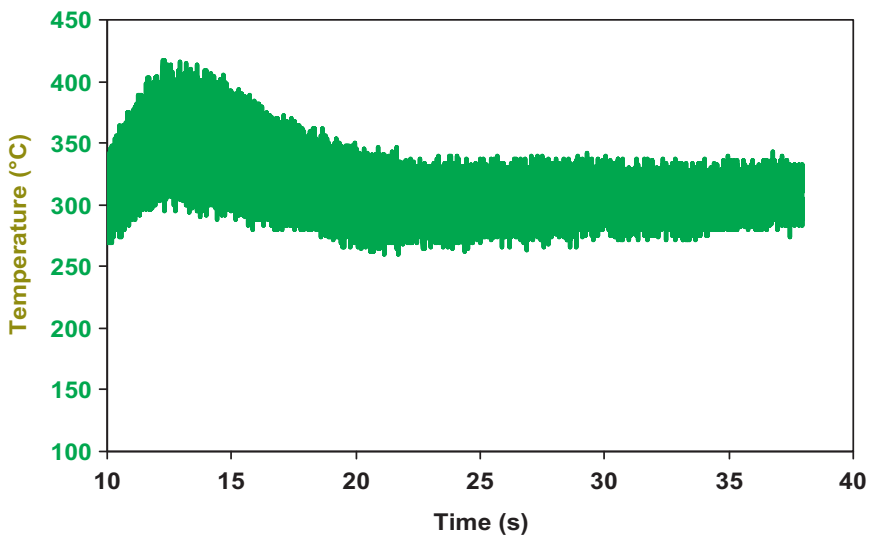

Fig. 6. Evolution of the real temperature on the average radius of the friction track (two-colour pyrometer measurements). a

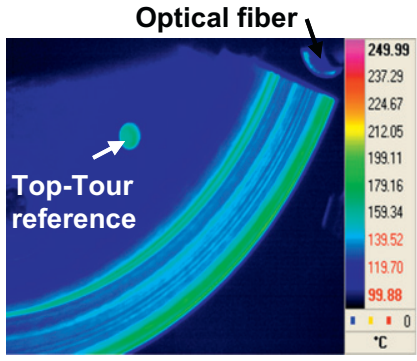

b

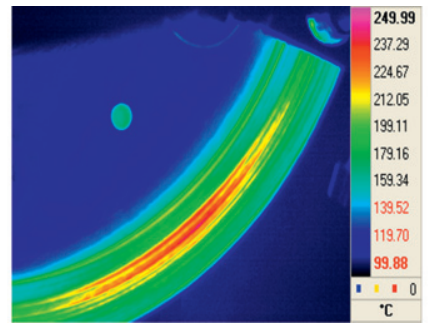

C

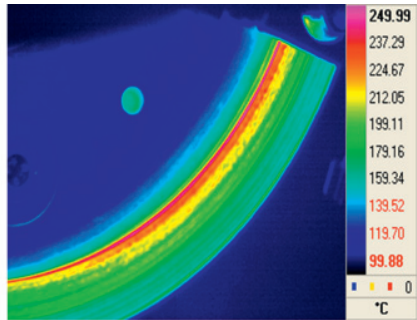

Fig. 5. IR thermography: (a) formation of a hot band in the outer radius, (b and c) migration of the hot band towards the inner radius. Temperatures calculated with emissivity equal to 1 . 


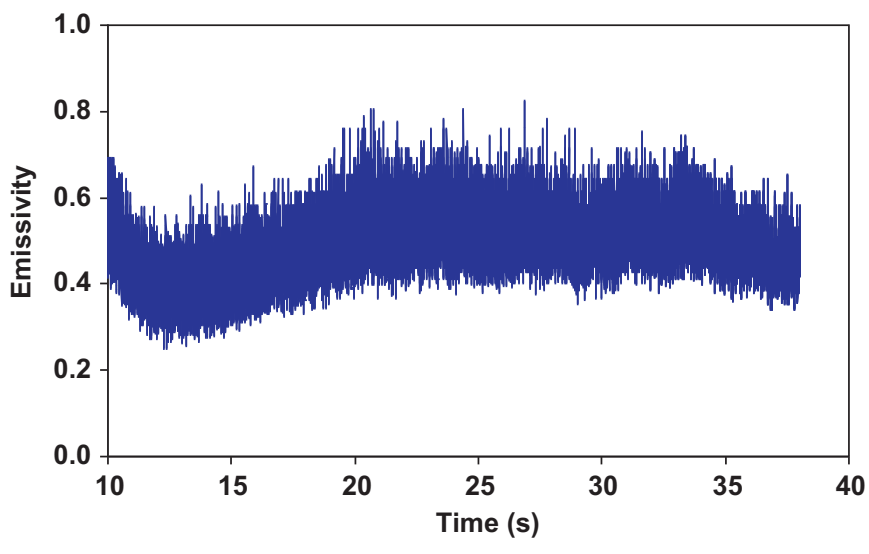

Fig. 7. Evolution of the surface on the average radius of the friction track emissivity (two-colour pyrometer measurements).

identify the predominant factor among these, we analysed the relative contribution of each of them.

- Surface temperature: Bauer et al. studied the temperature dependencies of the surface emissivity for several metals [26]. The authors showed that for pre-oxidized steel, temperature affects the surface emissivity value very slightly $(\Delta \varepsilon<0.03$ for temperatures ranging between 200 and $800^{\circ} \mathrm{C}$ at $\lambda=4 \mu \mathrm{m}$ ). In our case, the average temperature only increases from 310 $(t=13 \mathrm{~s})$ to $350^{\circ} \mathrm{C}(t=20 \mathrm{~s})$ while emissivity decreases from 0.55 to 0.4 . These different ratio variations between temperature and emissivity allow one to reject the hypothesis supporting only the role of temperature variation in emissivity decrease.

- Surface roughness: At the end of braking, friction is localized on the inner part of the friction track, the surface of the average friction radius is no longer subjected to friction (see Fig. 6c). The surface roughness on the average radius is thus assumed to remain constant once the hot band has moved towards the inner radius $(t>13 \mathrm{~s})$. However, while surface roughness remains constant, the surface emissivity increases once again after the formation of the hot band on the average radius. This consequently allows one to minimise the role of the surface roughness in emissivity variation.

- Physicochemical properties of the surface: At the beginning of braking, friction is localized in the outer radius and the surface of the average radius is not subjected to friction and assumed to be oxidized (presence of oxide coatings). Moreover, knowing that oxide coatings have an elevated emissivity [24,25], this explains the elevated emissivity value $(\varepsilon=0.55)$ in the average radius at the beginning of braking. When the hot band migrates towards the average radius, oxide coatings are inevitably reduced by friction (sharing) leading to emissivity decreases. Finally, when the hot band crosses the average radius towards the inner one, the disc surface at the average radius is exposed to a strong oxidation which takes into account the elevated temperature and the presence of oxygen in the atmosphere. Thus oxide coatings reform rapidly leading to emissivity increases again.

The analysis of the different factors shows that, in our case (braking), the emissivity variation is mainly due to the surfaces physicochemical properties evolution (elimination and reforming of oxide coatings on the disc surface) caused by a change in local friction conditions.

Fig. 8 shows the instantaneous variation of the real temperature and the emissivity between 15.5 and $15.74 \mathrm{~s}$. The

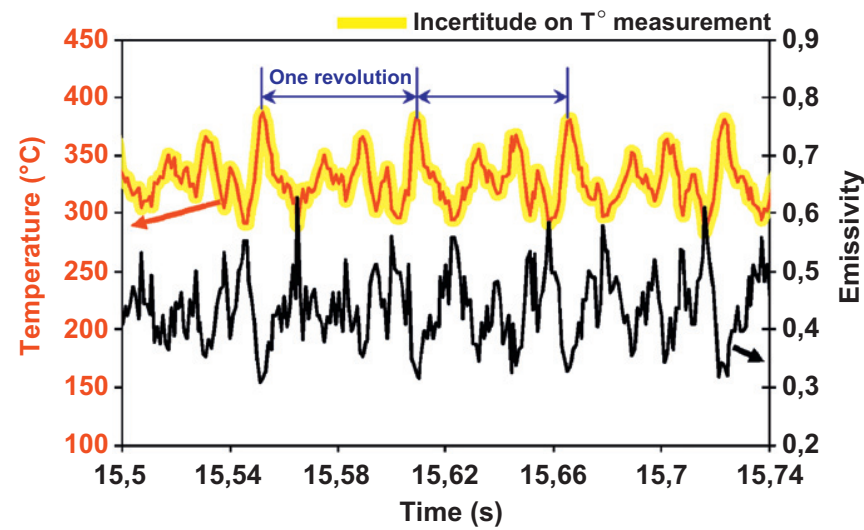

Fig. 8. Evolution of the real temperature and surface emissivity on the average radius for successive revolutions.

uncertainty of the measured temperature (calculated with the signals obtained by the two-colour pyrometer) is lower than $8{ }^{\circ} \mathrm{C}$ for temperatures above $300^{\circ} \mathrm{C}$, in addition this uncertainty decreases when the temperature increases [19]. Indeed the yellow line in Fig. 8 presents the maximum uncertainty of the measured two-colour temperature. We can see that the surface temperature fluctuations express in reality circumferential thermal gradients. In addition it can be seen that the emissivity decreases with the increase in temperature. As explained above, this emissivity decrease mainly results from a local modification of the surface's physicochemical properties (elimination of oxide coatings by friction). This result correlates well with the literature showing that at $400{ }^{\circ} \mathrm{C}$ bright steel has emissivity values ranging between 0.3 and 0.35 for wavelengths between 2.5 and $5 \mu \mathrm{m}$ [26].

\subsubsection{Coupling between IR thermography and two-colour pyrometer measurements}

The real temperature and the surface emissivity are given by the two-colour pyrometer measurements. In order to correct the temperature measured by the IR camera, the value of the surface emissivity is reintroduced in the post-treatment of measurements obtained by the IR camera.

Fig. 9 gives the profile variations of the real temperature and the surface emissivity for $15.687 \mathrm{~s}<t>15.697 \mathrm{~s}$ (see blue arrows) given by the two-colour pyrometer. The average temperature of the considered profile is $335.4 \pm 12.7^{\circ} \mathrm{C}$ and the average emissivity is $0.44 \pm 0.05$. Fig. 10a gives the thermography of the disc surface at $t=15.7 \mathrm{~s}$ at which the profile corresponds to the same area as where the temperature and emissivity profiles reported in Fig. 9 are calculated. Fig. 10b gives the two corresponding temperature profiles on the average radius of the friction track; one was calculated with emissivity 1 (blackbody behaviour of the brake disc) while the second was calculated with emissivity equal to 0.44 (value obtained by the two-colour pyrometer measurements). The average temperature was also calculated for both profiles (emissivity 1 and 0.44 ): it is equal to $244.6 \pm 5.9^{\circ} \mathrm{C}$ for emissivity 1 and $344 \pm 6.5^{\circ} \mathrm{C}$ when the corrected emissivity value is used (0.44). For the IR camera image, the average temperature calculated with the corrected emissivity (0.44) is very close to that found by the two-colour pyrometer $\left(\Delta T=8.6^{\circ} \mathrm{C}\right)$, whereas the average temperature calculated with emissivity 1 is very low when compared to that found by the two-colour pyrometer $\left(\Delta T=90.8^{\circ} \mathrm{C}\right)$. It can be clearly seen that the correction of the IR thermography temperature, by using the corrected emissivity value, allows one to significantly reduce the error on measured temperature. However, when the average corrected emissivity is considered in IR thermography, 
the circumferential thermal gradients are inevitably smaller than those found by the two-colour pyrometer (compare thermal gradients in Figs. 9 and 10b).

\subsection{Correlation between tribological behaviour and surface temperature}

In order to study the origin of the surface temperature fluctuations, we correlated them with the instantaneous variation of the normal and tangential forces measured in the contact with

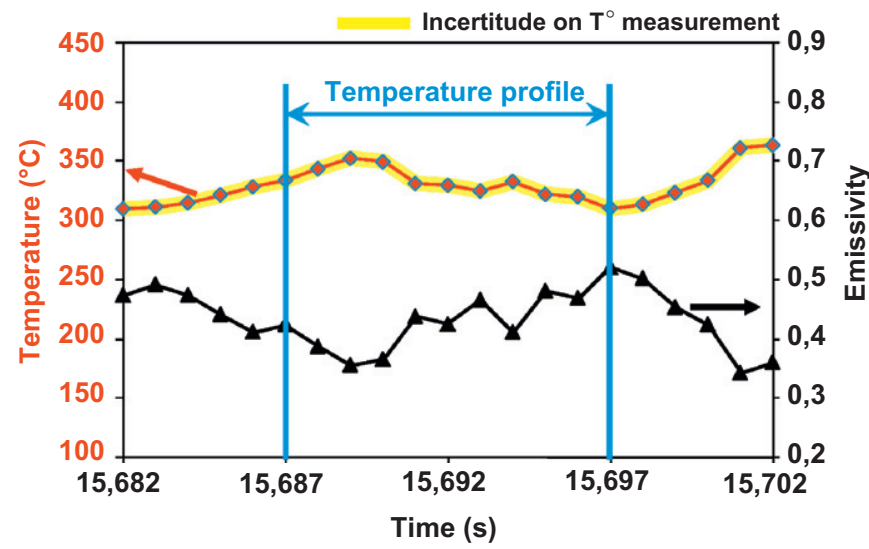

Fig 9. Evolution of the real temperature and surface emissivity on the average radius. Temperature profile corresponds to those of the IR thermography presented in Fig. 10. the piezoelectric forces sensor, during $(t=13 \mathrm{~s})$ and after $(t=20 \mathrm{~s})$ the occurrence of the hot band at the average friction radius. Taking into account the fact that forces are measured in contact while temperature is measured at $90^{\circ}$ disc rotation from the contact, this shift was systematically adjusted by advancing the temperature signal of 18 and $24 \mathrm{~ms}$, respectively. The increase of the delay between the forces and the temperature fluctuations with time of sliding is due to the deceleration of the disc rotation, knowing that the acquisition frequency remains constant for both forces and temperature measurements $(1 \mathrm{kHz})$.

Figs. 11 and 12 illustrate respectively the variations of the temperature and normal force and temperature and tangential force at $t=13$ and $20 \mathrm{~s}$. As can be seen, the temperature fluctuations are well correlated with the normal and tangential forces' variations in contact. This good correlation allows us to connect temperature variation to the evolution of contact conditions and to reject the possibility of measurement artefacts. Increase of loading is due to circumferential disc thermomechanical deformation, which is well known in braking [5]. Furthermore, we can see that the normal and tangential forces follow the same evolution leading to a quasi constant value of friction coefficient (Fig. 13). This result shows that the increase in temperature corresponds to an increase in loading and consequently to heat-flux.

\section{Conclusion}

The surface temperature variation during railway stop-braking was studied using a two-colour pyrometer and an IR camera.



b

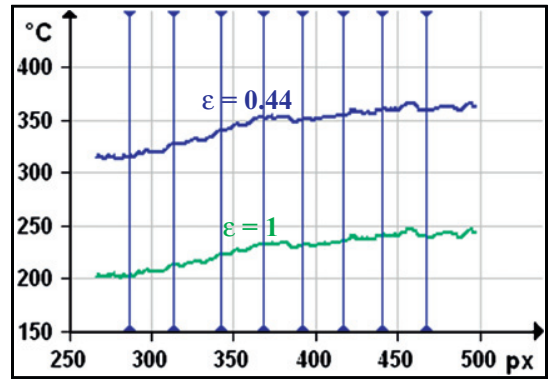

Fig 10. (a) IR thermography of the disc at $t=15.7 \mathrm{~s}$, (b) temperature profiles on the average radius with different emissivities.

a

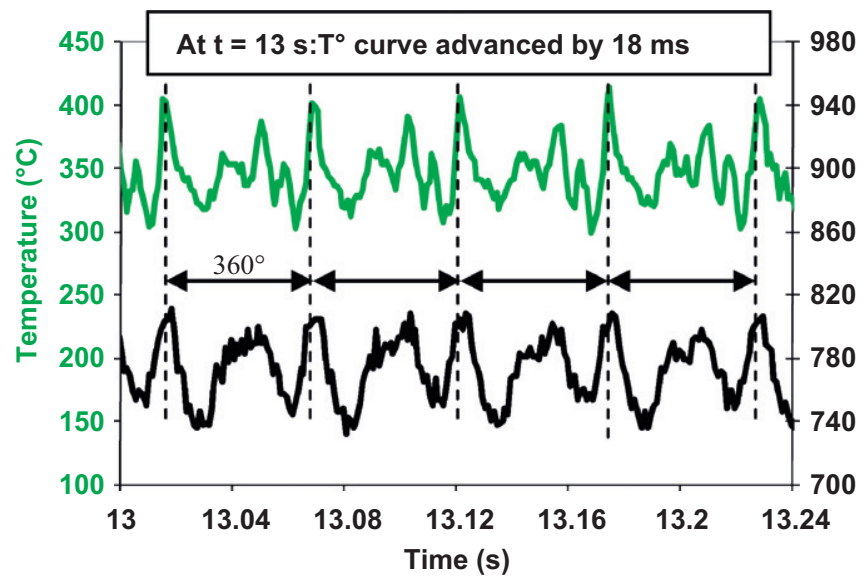

b

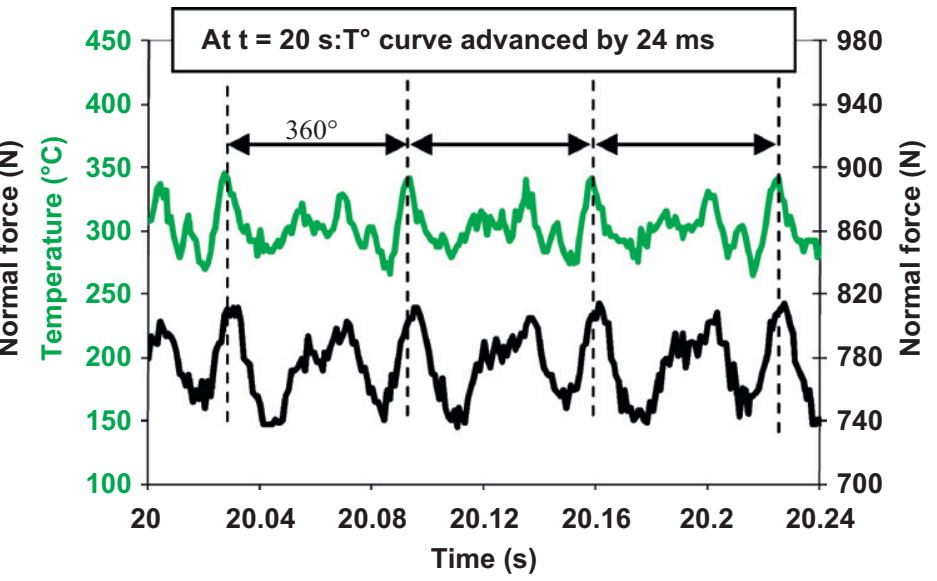

Fig. 11. Variations of the real temperature on the average radius and normal force at $t=13$ and $20 \mathrm{~s}$. 
a

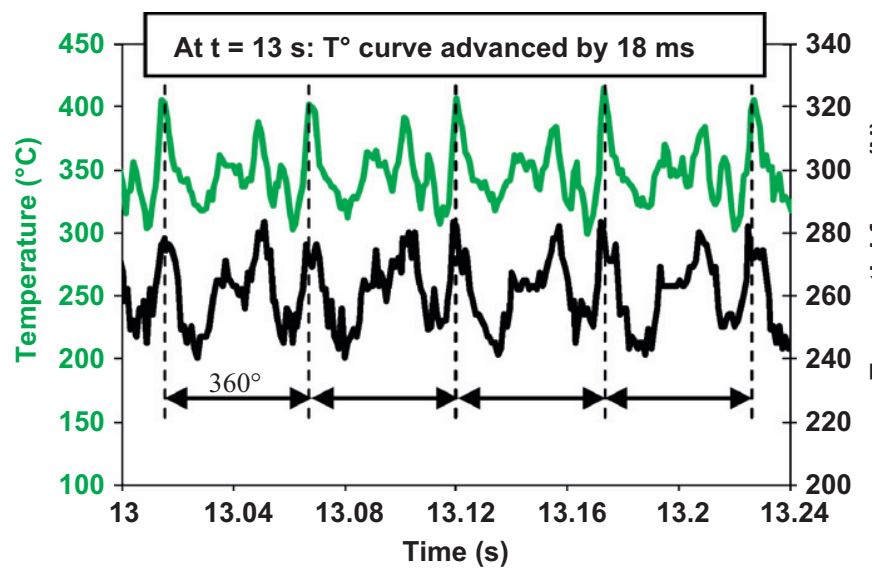

b

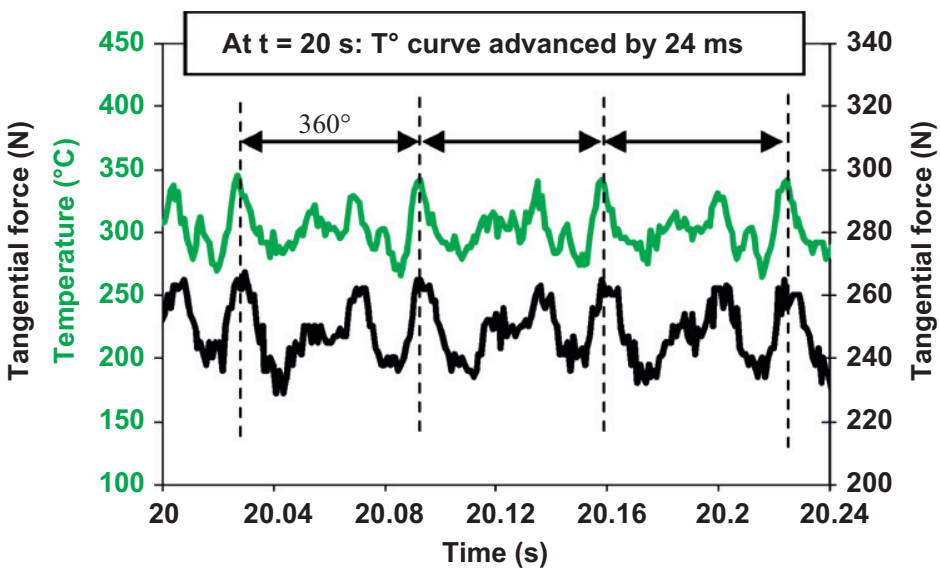

Fig. 12. Variations of the real temperature on the average radius and tangential force at $t=13$ and $20 \mathrm{~s}$.

a

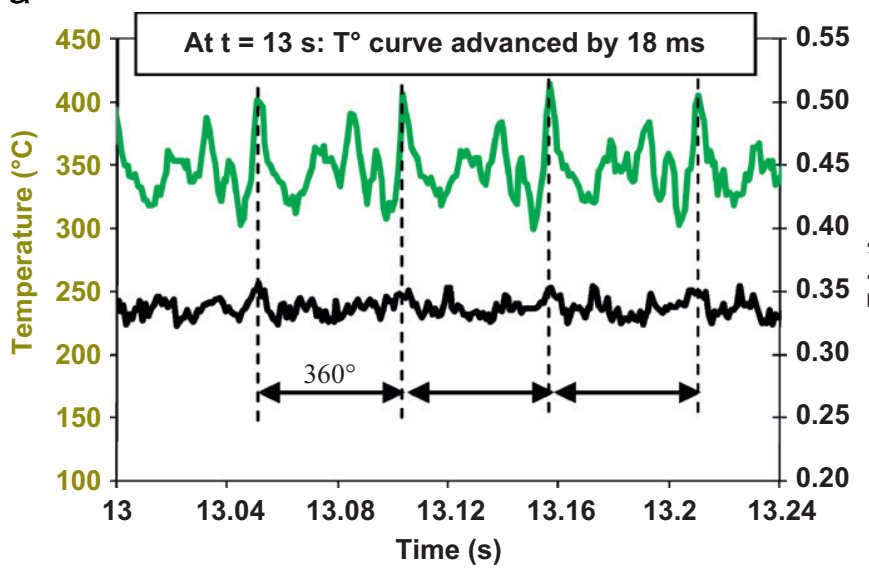

b

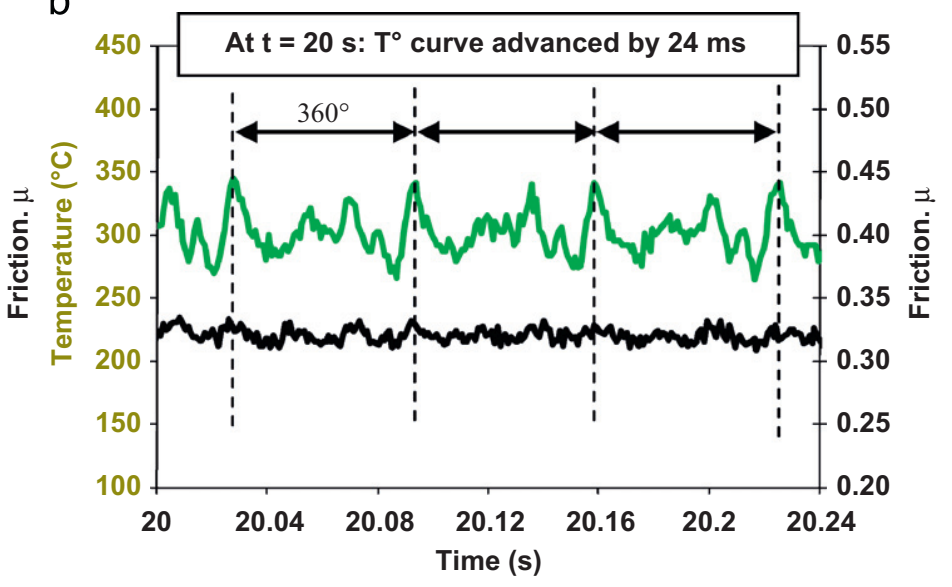

Fig 13. Variations of the real temperature on the average radius and friction coefficient at $t=13$ and $20 \mathrm{~s}$.

Stop-braking experiments were performed on a pin-on-disc tribometer and the frictional pair was composed of a pad made of organic matrix composite and a disc made of XC-48 steel. The two-colour pyrometer measurements give the evolutions of both the real temperature and the surface emissivity which are interpreted according to the variations of the surface contact conditions.

At the beginning of stop-braking, a hot band forms systematically on the outer radius of the friction track, it then migrates progressively towards the inner radius. It is shown that this hot band migration, due to contact localization, leads to an increase in the temperature and decrease in the surface emissivity due to the evolution of contact conditions (such as elimination of oxide coatings).

The emissivity is found to be very heterogeneous on the disc surface and changes rapidly with local friction conditions evolution (such as occurrence of the hot band). Thus, the consideration of a constant emissivity value is not appropriate for radiometric temperature measurement in braking applications. To correct the temperature obtained by the IR camera in this study we coupled both two-colour pyrometer and IR camera measurements. By using the corrected emissivity value given by the two-colour pyrometer, the actual values of surface temperature can be measured more accurately. In addition, we illustrate that only the use of IR thermography leads to an underestimation of the circumferential thermal gradient. Thus, by coupling IR thermography and a two-colour pyrometer we can better estimate the errors on the measured surface temperature due to unknown emissivity when using an IR camera communally used. The rapid variations of emissivity value with change in contact conditions must be taken into consideration in radiometric temperature measurement in braking and could be especially useful in the verification of friction surface temperature predictions.

Finally, being well correlated with the normal and tangential forces variations in contact, the fluctuations of the temperature measured by the two-colour pyrometer are due to an evolution in contact conditions.

\section{Acknowledgements}

The present research work has been supported by International Campus on Safety and Intermodality in Transportation, the Nord-Pas-de-Calais Region, the European Community, the Regional Delegation for Research and Technology, the Ministry of Higher Education and Research, and the National Center for Scientific Research. 


\section{References}

[1] Kennedy FE. Thermal and thermomechanical effects in dry sliding. Wear 1984;100(1-3):453-76.

[2] Anderson AE, Knapp RA. Hot spotting in automotive friction systems. Wear 1990;135:319-37.

[3] Panier S, Dufrénoy P, Weichert D. An experimental investigation of hot spots in railway disc brakes. Wear 2004;256:764-73.

[4] Cristol-Bulthé A-L, Desplanques Y, Degallaix G, Berthier Y. Mechanical and chemical investigation of the temperature influence on the tribological mechanisms occurring in OMC/cast iron friction contact. Wear 2008;264:815-25.

[5] Dufrénoy P, Bodovillé G, Degallaix G. Damage mechanisms and thermomechanical loading of brake discs. European Structural Integrity Society 2002;29:167-76.

[6] Benillouche F, Pajani D, Bremond P, Potet P. Thermographie infrarouge d'objets tournant à grande vitesse. Ingénieurs de l'automobile 1992;667: 51-3.

[7] Majcherczak D, Dufrenoy P, Berthier Y, Nait-Abdelaziz M. Experimental thermal study of contact with third body. Wear 2006;261:467-76.

[8] Majcherczak D, Dufrenoy P, Berthier Y. Tribological, thermal and mechanical coupling aspects of the dry sliding contact. Tribology International 2007; 40:834-43.

[9] Kennedy F, Frusescu D, Li J. Thin film thermocouple arrays for sliding surface temperature measurement. Wear 1997;207:46-57.

[10] Qi HS, Day AJ. Investigation of disc/pad interface temperatures in friction braking. Wear 2007;262:505-13.

[11] Denape J, Laraqi N. Aspect thermique du frottement: mise en évidence expérimentale et éléments de modélisation. Mécanique \& Industries 2000;1:563-79.

[12] Cristol-Bulthé A-L, Desplanques Y, Degallaix G. Coupling between friction physical mechanisms and transient thermal phenomena involved in pad-disc contact during railway braking. Wear 2007;263: $1230-42$.

[13] Kasem H, Bonnamy S, Berthier Y, Dufrénoy P, Jacquemard P. Tribological, physicochemical and thermal study of the abrupt friction transition during carbon/carbon composite friction. Wear 2009;267:846-52.
[14] Siroux M, Harmand S, Desmet B. Experimental study using infrared thermography on the convective heat transfer of a TGV brake disc in the actual environment. Optical Engineering 2002;41(7):1558-64.

[15] Siroux M, Bulthe A-L, Desplanques Y, Desmet B, Degallaix G. Thermal analysis of periodic sliding contact on a braking tribometer. Applied Therma Engineering 2008;28:2194-202.

[16] Cartigny F, Copin R, Siroux M, Harmand S, Desplanques Y, Degallaix G, et al Cartographies d'émissivité de la surface d'un disque de frein. Congrès SFT Lyon 2000:351-6.

[17] Desmet B, Siroux M, Cartigny F, Harmand S, Desplanques Y, Degallaix G. Métrologie thermique du contact en freinage. In: European conference on braking JEF. Lille; 2002. p. 369-376.

[18] Thevenet J, Siroux M, Desmet B. Brake disc surface temperature measurement using a fiber optic two-color pyrometer. In: Ninth international conference on quantitative infrared thermography QIRT 2008 proceeding. Krakow Juillet; 2008. p. 87-94. ISBN 978-83-908655-1-5.

[19] Thevenet J. Développement d'une métrologie thermique des contacts glissants en freiange. Thèse de doctorat, Université de Valenciennes, Juillet; 2009.

20] Desplanques Y, Degallaix G, Copin R, Berthier Y. A tribometer for the study of materials under railway braking conditions. In: Dalmaz G, editor. Tribology research: from model experiment to industrial problem. Amsterdam: Elsevier; 2001. p. 381-91.

[21] Desplanques Y, Roussette O, Degallaix G, Copin R, Berthier Y. Analysis of tribological behaviour of pad-disc contact in railway braking. Part 1 Laboratory test development, compromises between actual and simulated tribological triplets. Wear 2007;262:582-91.

[22] Cabannes F. Pyrométrie optique, traité: mesures et contrôle. Techniques de l'ingénieur; 1990. p. R2610.

[23] Ferdinand P. Thermomètres à fibre optique sans contact. Techniques de l'ingénieur; 2003. p. R2801.

[24] Hervé P. Mesure de l'émissivité thermique. Techniques de l'ingénieur; 2005 p. R2737.

[25] Hladik J. Métrologie des propriétés thermophysiques des matériaux. Masson; 1990.

[26] Bauer W, Oertel H, Rink M. Spectral emissivity of bright and oxyded metals at high temperatures. In: Fifteenth symposium on thermophysical properties, Boulder, Colorado; 2003. 